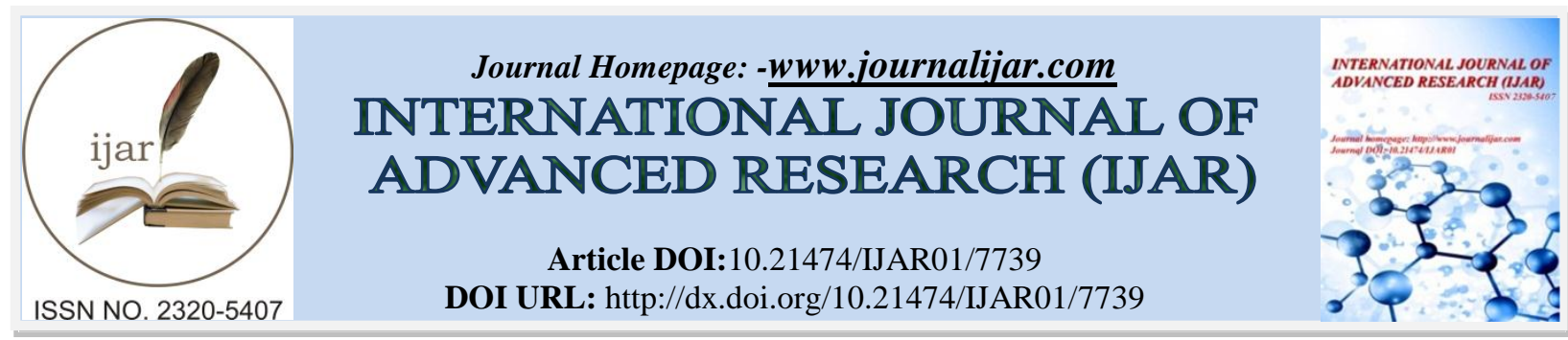

RESEARCH ARTICLE

\title{
DYNAMIC VISCOELASTIC PROPERTIES OF HEAT CURED AND INJECTION MOLDED THERMOPLASTIC DENTURE RESINS.
}

Asmaa N. Elboraey ${ }^{1}$, Amani R. Moussa ${ }^{2}$, Dalia Y. Zaki ${ }^{3}$ and Sherihan M. Eissa ${ }^{4}$.

1. Researcher, Fixed\& Removable Prosthodontics Dep., National Research Centre (NRC), Cairo, Egypt.

2. Ass Prof, Fixed \& Removable Prosthodontics Dep., National Research Centre (NRC), Cairo, Egypt.

3. Ass Prof, Restorative \& Dental Materials Dep, National Research Centre (NRC), Cairo, Egypt.

4. Researcher, Fixed \& Removable Prosthodontics Dep., National Research Centre (NRC), Cairo, Egypt.

\section{Manuscript Info}

(.........................

Manuscript History

Received: 23 July 2018

Final Accepted: 29 August 2018

Published: September 2018

Keywords:-

Poly-methyl-methacrylate, Thermoplastic resin, Viscoelastic properties, Dynamic mechanical thermal analysis.

\section{Abstract}

Background: Poly methyl methacrylate (PMMA) resin is still the most commonly used material for denture bases despite of their known disadvantages. Attempts to overcome these problems were approached through the introduction of new denture base materials including the injection molded thermoplastic resins.

Objective: The purpose of this study was to evaluate and compare the viscoelastic behavior of conventional heat cured and injection molded thermoplastic resins over wide range of thermal variation.

Materials and Methods: A total number of 90 Specimens were prepared. 45 specimens for conventional heat cured resin (Vertex regular, Zeist, Netherlands) and 45 specimens for thermoplastic injection molding denture base materials (Bre-Crystal, Bredent, Germany) were polymerized according to their manufacturer instructions. The Dynamic mechanical thermal analysis at a frequency of $1 \mathrm{~Hz}$ under shearing mode and over a temperature range of 5 to 50 ${ }^{0} \mathrm{C}$ was carried out using a dynamic viscoelastometer. The shear storage modulus $\left(\mathrm{G}^{\prime}\right)$, the loss modulus $\left(\mathrm{G}^{\prime \prime}\right)$, and damping factor $(\tan \delta$ ) were obtained.

Results: Significant differences were detected between the two tested materials regarding storage and loss moduli. Higher mean storage and loss moduli and damping factors were recorded for the heat cured resin compared to thermoplastic injection molded resin.

Conclusion: Within the limitations of this study it could be concluded that different types of denture base materials and processing techniques affect the dynamic viscoelastic properties and consequently could influence their clinical performance in the oral environment. The regular clinical use of thermoplastic resin should be considered in special cases. 


\section{Introduction:-}

Heat cured poly methyl methacrylate (PMMA) resin material is the most commonly used denture base material, for its known advantages of: ease of processing, biocompatibility, reasonable price, acceptable esthetic and stability. However, dimensional instability and low mechanical properties are among its major drawbacks.

During function acrylic resin dentures are subjected to repeated tensile, shear, and compressive stresses and due to its known low toughness, material failure may result. Mean while, their low impact strength subjects the material to failure under high-impact forces [1,2].

To overcome these drawbacks modifications have been made through; fibers reinforcement, addition of various copolymers [3] and via the introduction of new processing techniques as light-curing, injection-molding and microwave-curing of resins [4-6]. An alternative denture base polymers were introduced such as thermoplastic PMMA resin, polyacetal and polyamide [7-8].

Thermoplastic PMMA is a polymerized acrylate, prepared through blending of methyl methacrylate with other polymers to improve the impact strength, and is mostly used for the fabrication of complete denture bases. Among the important featuresof thermoplastic PMMA are: biocompatibility, non-allergenic (monomer-free), enhanced esthetics, smooth dense texture; therefore it is more comfortable for the patients [9].

Mechanical properties of injection-molded thermoplastic denture base resins under static load were examined in previous studies [10-12]. However intraorally; dentures are subjected to cyclic thermal and mechanical stresses [1314], that may adversely affect their mechanical behavior, hence their serviceability and durability [15-16]. It is paramount therefore, to simulate the clinical conditions during the evaluation of these denture base materials.

Dynamic mechanical thermal analysis (DMTA) is one of the most accurate methods used to determine viscoelastic behavior of polymeric materials over a wide range of temperature and frequencies. This useful tool is used to estimate the viscoelastic properties of denture base materials and soft liners [17-18].

In DMTA three important rheological parameters are measured including: storage modulus $\left(G^{\prime}\right)$, loss modulus $\left(G^{\prime \prime}\right)$, and damping factor $(\tan \delta)$. $G^{\prime}$ defines the elastic deformation under stress, whereas $G^{\prime \prime}$ displays the viscous deformation, while $(\tan \delta)$ demonstrates the relative contribution of the elastic and in- elastic components explaining the overall material behavior [19].

Despite the earlier studies on mechanical properties and wear resistance, little information is available about the viscoelastic properties of thermoplastic denture base resins. The hypothesis was that the viscoelastic properties of injection-molded thermoplastic denture differs from that of conventional heat cured acrylic resin base resins which may affect the clinical performance of removable dentures.

Hence, the purpose of this study was to evaluate and compare the viscoelastic behavior of heat cured and injection molded thermoplastic resins; using the dynamic mechanical testing method, over the temperature range of the oral cavity.

\section{Materials and Methods:-}

The two tested denture base materials; their manufacturers and batch numbers are listed in table (1).

Table .1:-Denture base materials, their manufacturers and batch numbers:

\begin{tabular}{|l|l|l|}
\hline Material type & Manufacturer & Batch number \\
\hline $\begin{array}{l}\text { Conventional heat cured } \\
\text { acrylic resin }\end{array}$ & Vertex regular, Zeist, Netherlands & $\begin{array}{l}\text { Polymer: XR111P06 } \\
\text { Monomer: XR113L04 }\end{array}$ \\
\hline $\begin{array}{l}\text { Injection molded } \\
\text { thermoplastic resin }\end{array}$ & $\begin{array}{l}\text { Bredent-From Gmbh\& Co.KG, JB C240 } \\
\text { Germany }\end{array}$ & J \\
\hline
\end{tabular}

\section{Specimens preparation}

To prepare the test samples; stone molds (Kimberlit, Protechno, Spain) (30x10x1 mm) in dimensions were prepared by investing standardized plastic blanks in dental flasks. A total of 90 test samples were prepared from both 
materials and divided into two groups $(n=45)$ according to the type of denture base material. The heat cured PMMA samples were proportioned, mixed, packed and processed following the manufacturer instructions. While the thermoplastic resin samples were processed using injection-molding technique, following the manufacturer instructions.

\section{Dynamic mechanical thermal analysis:}

Dynamic viscoelastic properties of the prepared samples were measured using viscoelastometer (Anton Paar, MCR301 SN80218500, Austria, Europe). Samples were set in a shearing jig and tested at a frequency of $1 \mathrm{~Hz}$ at $0.7 \%$ strain [18]. Testing was done over temperature range from 5 to $50{ }^{0} \mathrm{C}$ and scanned at $3{ }^{0} \mathrm{C} / \mathrm{min}$. Each material's response was continuously measured regarding shear storage modulus $\left(G^{\prime}\right)$, shear loss modulus $\left(G^{\prime \prime}\right)$, and loss tangent $(\tan \delta)$, as a function of temperature.

\section{Statistical analysis}

Statistical analysis was performed using SPSS software package (Statistical Package for Social Sciences, version 10, SPSS Inc, Chicago, IL, USA). Comparisons of data were made by paired t test and $\mathrm{P}$ value was test at $p<0.05$ level to establish significance of differences. Pearson`s Correlation was performed to determine the relation of the measured parameters and temperature variations.

\section{Results:-}

Results of the tested denture base materials regarding the measured G', G " and tan $\delta$ values are shown in figures1 and 2 and listed in tables 2 and 3. Also, the effect of thermal variations on viscoelastic behavior $\left(G^{\prime}, G^{\prime \prime}\right.$ and tan $\left.\delta\right)$ of the two tested denture base materials are displayed in figures 3, 4 and 5. Comparison of the results of the two denture base materials showed large differences. The heat cured PMMA showed higher statistical significant mean values $(\mathrm{P}<0.05)$ regarding the three measured parameters $\left(\mathrm{G}^{\prime}, \mathrm{G}^{\prime}\right.$ and $\left.\tan \delta\right)$

Table 2:-The storage and loss modulus mean values $(\mathrm{Pa})$ and standard deviation (SD)forthe tested denture base materials:

\begin{tabular}{|l|lc|cc|}
\hline \multirow{2}{*}{ The tested parameter } & \multicolumn{3}{|c|}{ Material type } \\
\cline { 2 - 5 } & \multicolumn{1}{|c|}{ PMMA } & \multicolumn{2}{c|}{ Thermoplastic resin } \\
Mean & SD \\
\hline Storage Modulus & Mean & $9.17 \times 108 \quad \pm 1.11 \times 108$ & $3.87 \times 108$ & $\pm 0.194 \times 108$ \\
\hline Loss Modulus & $8.57 \times 10^{7} \quad \pm 1.02 \times 10^{7}$ & $.628 \times 10^{7}$ & $\pm 0.115 \times 10^{7}$ \\
\hline P-value & $0.00^{*}$ & & & \\
\hline
\end{tabular}

*Significant difference

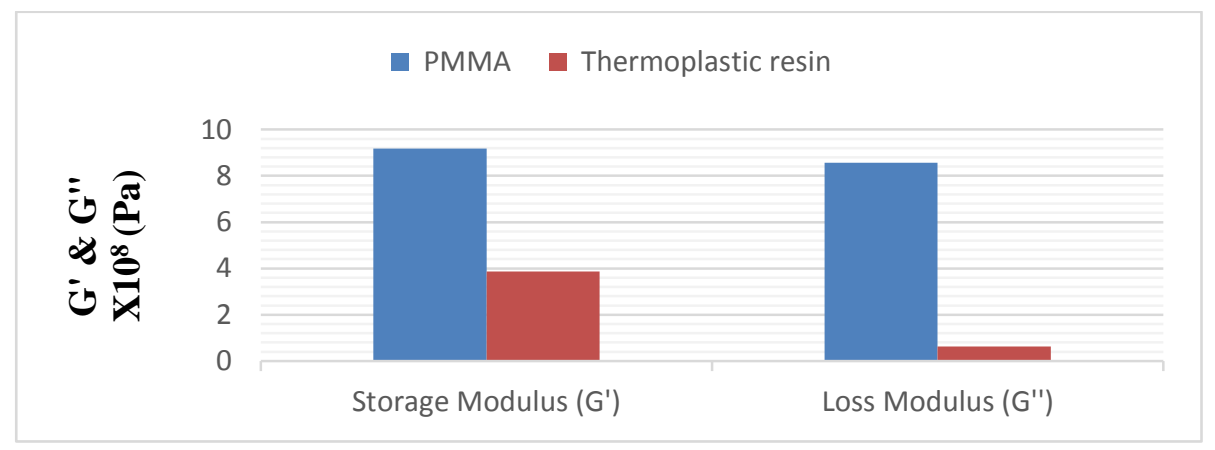

Fig. (1):-Bar chart of storageand loss moduli of PMMAand thermoplastic resins.

Table 3:-The damping factor mean values and standard deviation for the tested denture base materials:

\begin{tabular}{|c|c|c|}
\hline \multirow[t]{3}{*}{ The tested parameter } & \multicolumn{2}{|c|}{ Material type } \\
\hline & PMMA & Thermoplastic resin \\
\hline & Mean SD & Mean SD \\
\hline Damping Factor & $0.093 \pm .001$ & 0.0164 \\
\hline
\end{tabular}




\begin{tabular}{|l|l|l|}
\hline P-value & $0.00 *$ \\
\hline
\end{tabular}

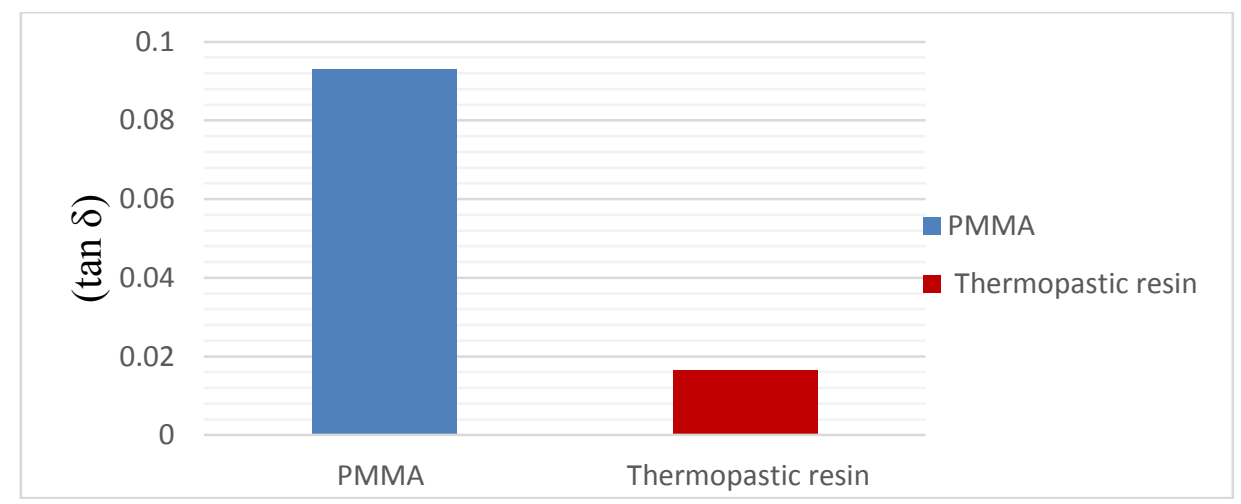

Fig. 2:-Bar chart of damping factor of PMMA and thermoplastic resins

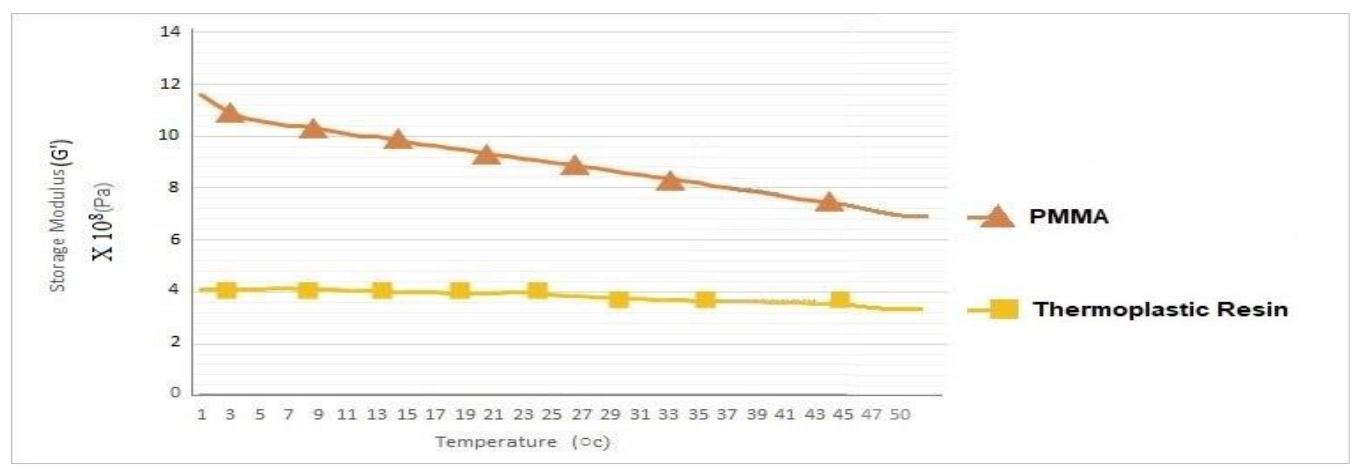

Fig 3:-Effect of temperature changes on storage modulusof PMMA and thermoplastic resins

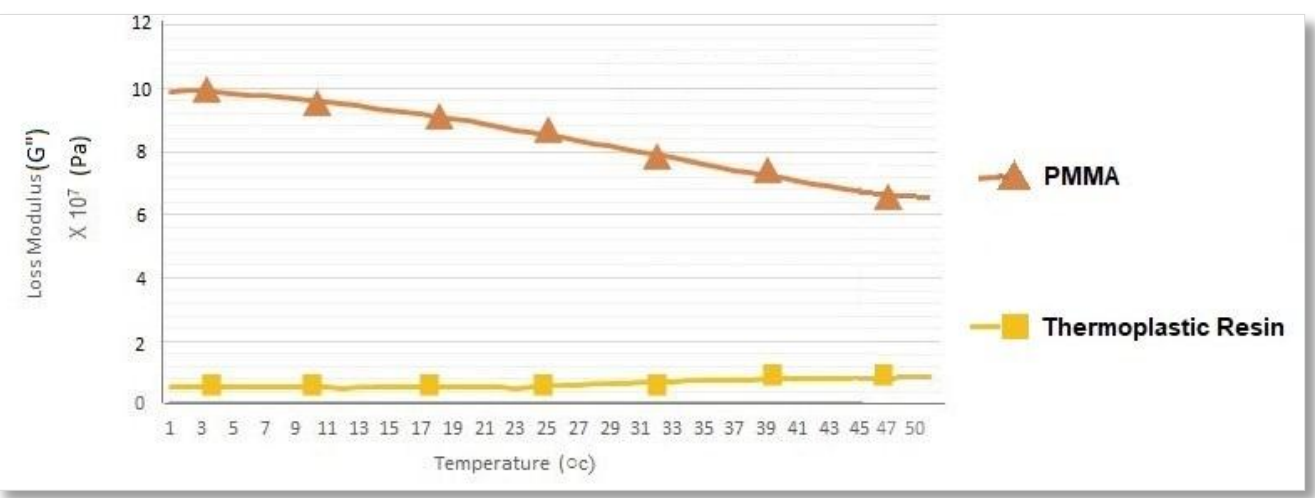

Figure 4:-Effect of temperature changes on loss modulus of PMMA and thermoplastic resins 


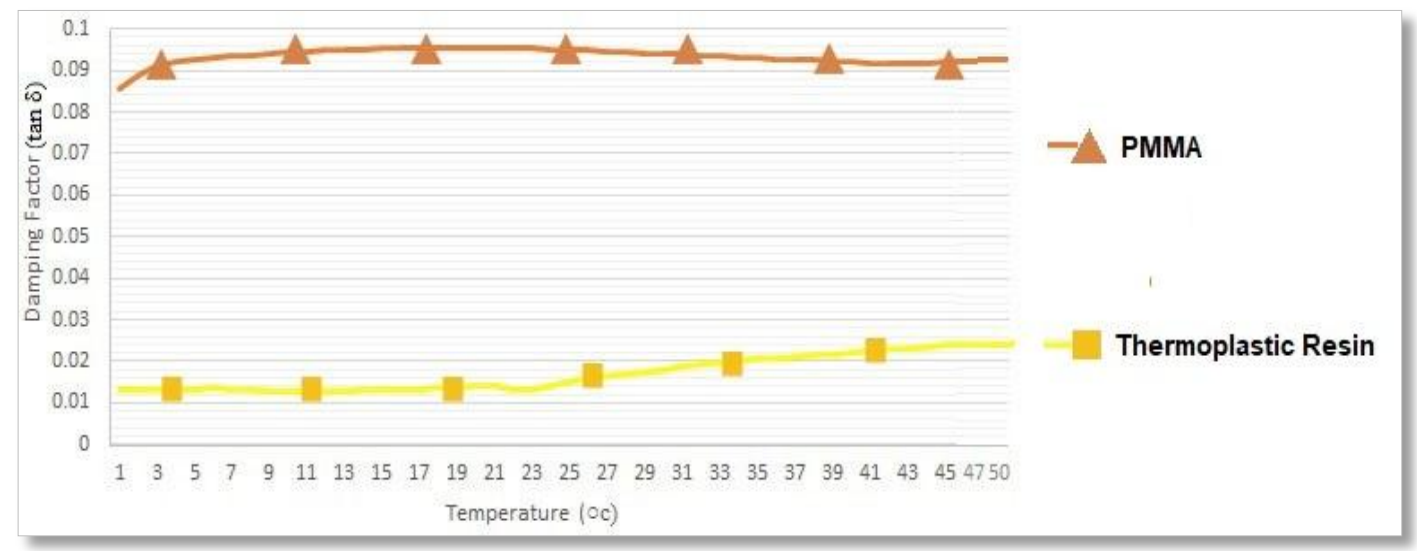

Fig 5:-Effect of temperature changes on damping factorof PMMAand thermoplastic resins

As shown in Fig. 3, There was a gradual decrease in G' values of PMMAapproaching approximately half of it is value by increasing temperature to $50^{\circ} \mathrm{C}$. On the other hand, the thermoplastic resin showed a relative stability with the increase in the temperature. The same behavior of the two materials regarding the G" was observed with less sharp decrease regarding the heat cured resin with the increase in temperature.

Comparing the damping factor $(\tan \delta$ ) of the two materials, the PMMA showed a higher statistical significant difference value than thermoplastic resin at the tested temperature range as $\mathrm{P}$ value was less than 0.05.It is also noticed that thermoplastic resin revealed slight gradual increase in $\tan \delta$ values above $19{ }^{\circ} \mathrm{C}$ up to $50{ }^{\circ} \mathrm{C}$ (Fig. 5).

When performing Pearson`s Correlation for G', G" and $\tan \delta$ with temperature changes, there were strong negative correlation between $\mathrm{G}^{\prime}, \mathrm{G}^{\prime \prime}$ and temperature increase for heat cured resin. Thermoplastic resin on the other hand, showed a week positive correlation between $G^{\prime}, G^{\prime \prime}$ with the temperature increase (Fig. 3\&4). Furthermore, there was strong positive correlation between $\tan \delta$ and temperature increase for both denture base materials (Fig. 5).

\section{Discussion:-}

Injection molding is a procedure in which a heated polymeric material is injected into a mold cavity with the required dimensions at very high pressure. This technique allowed the use of new thermoplastic resins as alternative to heat cured PMMA, without the need for chemical additives or catalysts that may be allergic for patients [10, 21].

Studies on the static mechanical properties of thermoplastic resins demonstrated that they all had significantly lower elastic modulus, lower flexural strength at the proportional limit, and higher or the same impact strength when compared with the heat cured PMMA type. Mean while; permanent deformations without fracture occurred in the thermoplastic resins, while all acrylic resin specimens fractured [10, 22].

The viscoelastic behavior of the thermoplastic materials under fluctuation of thermal and mechanical stresses is required to ensure its clinical performance. Therefore, DMTA method was used in this study to evaluate and compare the viscoelastic characteristics of the heat cured PMMA and injection molded thermoplastic resins. A constant frequency of $1 \mathrm{~Hz}$ and a temperature range from $5-50{ }^{\circ} \mathrm{C}$ was used; to simulate the masticatory rhythm [23], and the temperature range in the oral environment respectively [13].

The higher $G^{\prime}$ value recorded for heat cured resin indicates its higher rigidity when compared with that of the thermoplastic type which showed more flexibility. As well, higher G" value was also evident for the heat cured resin type describing its ability to provide more deformation under dynamic stresses.

The ratio between G' $/ G^{\prime}$ is tan $\delta$ and is an important measure in deciding the material behavior.

The higher significant tanorecorded for the heat cured resin indicates their viscoelastic behavior and higher level of cushioning effect; when compared with the thermoplastic type that showed more elastic behavior with $\tan \delta$ approaching zero. Higher tan $\delta$ value of heat cured type is an indication of its ability to dissipate more energy into heat, and greater molecular mobility [24].Therefore; the ability of the heat cured type to absorb energy and relieve 
stress is greater than that of the thermoplastic type with lower $\tan \delta$ values.Such findings support the hypothesis postulated for this study.

A correlation between the viscoelastic behavior of the denture base material and the masticatory function was noticed. A greater improvement in masticatory function was found in materials having high $\tan \delta$ value and storage modulus, at $1 \mathrm{~Hz}$, where a degree of stress relief takes place under masticatory forces [18]. The higher storage modulus of heat cured type may indicate its better masticatory performance for direct crushing of food than the thermoplastic type.

In light of these results, the regular clinical use of thermoplastic resin should be taken into consideration. Such findings are in agreement with results of previous studies that recommended the use of thermoplastic resins as alternative to conventional PMMA resins incertain clinical situations such as repeated denture fracture and the presence of tissue undercuts $[10,21,25]$.

Results also demonstrated that the gradual decrease in $\mathrm{G}^{\prime}$ value of heat cured resin with the increase in temperature up to $50^{\circ} \mathrm{C}$; revealing sensitivity of the material to temperature increase, with reduction in materials' rigidity. However, the $\mathrm{G}^{\prime}$ value of heat cured resin at $50^{\circ} \mathrm{C}$ is still significantly higher when compared with that of the thermoplastic type, which showed a relative less temperature sensitivity. Furthermore, the same pattern regarding G"; for the two tested materials was observed with less sharp decrease regarding the heat cured resin with the increase in temperature.

For the thermoplastic resin, the increase in tan $\delta$ value by temperature increase from $19^{\circ} \mathrm{C}$ to $50^{\circ} \mathrm{C}$, demonstrates the increase in molecular mobility above $19^{\circ} \mathrm{C}$. On the contrary the tan $\delta$ value of the heat-cured type was less affected through the tested temperature range. The increase in $\tan \delta$ value with the increase in temperature may indicate that the material is approaching the rubbery state. However; the values of $\tan \delta$ of both materials are less than one up to $50^{\circ} \mathrm{C}$, demonstrating that both materials remained in the solid state through the tested temperature range.

The differences in chemical composition and structure of the polymer as the molecular weight, particle size, crosslinking agent, blending different polymer types as well as the difference in the processing techniques are important influencing factors that may explain the variation in the viscoelastic behavior of the two tested denture base materials. The exact composition of the thermoplastic resin as a denture base material is not known. However, the known general characteristics of thermoplastic polymers of having a high molecular weight and their bonding together through intermolecular forces, in contrast to that of thermoset polymer where chemical bonding i.e. cross linking produced during the curing process, may explain the differences in viscoelastic response of the tested materials [26].

\section{Conclusion:-}

Within the limitations of this study it could be concluded that:

1. The type of denture base material and processing techniques affect the viscoelastic behavior which could affect the clinical performance of the denture base material.

2. Heat cured resin type showed higher cushioning effect as revealed by higher damping factor and storage modulus when compared with the thermoplastic type.

3. The higher damping factor and storage modulus of heat cured resin type may indicate its positive impact on the masticatory performance, when compared with the thermoplastic type.

4. Thermoplastic material should not be considered as a substitution for the heat cured resin for all clinical cases. Its higher elastic behavior favors its use in situations with repeated denture fracture or when tissue undercuts exist.

\section{Competing interest statement:}

The authors declared no competing interests.

\section{Source of support:}

This research did not receive any specific grant from funding agencies in the public, commercial, or not for profit sectors. 


\section{Acknowledgment:-}

None

\section{Conflict of Interest:}

The authors declare no conflict of interest. The authors alone are responsible for the content and writing of the paper.

\section{Author contributions:}

Asmaa N. Elboraey, Amani R. Moussa and Dalia Y. Zaki conceived the idea and drafted the paper. Sherihan M. Eissa carried out the statistical analysis and the interpretation of the results. Dalia Y. Zaki was responsible for the practical part of the research. Asmaa N. Elboraey, Amani R. Moussa and Dalia Y. Zaki wrote the paper and revised the final version of the paper. All authors equally shared in financing cost of the research paper.

\section{References:-}

1. Furuya-Yoshinaka M, Yoshinaka M, Isogai F, Maeda Y. Influence of an experimental palatal plate on thermal perception. J Prosthodont Res 2009;53:193-6.

2. Pero AC, Marra J, Paleari AG, Pereira WR, Barbosa DB, Compagnoni MA. Measurement of interfacial porosity at the acrylic resin/denture tooth interface. J Prosthodont 2010; 19:42-6

3. John J, Gangadhar SA, Shah I. Flexural strength of heat-polymerized polymethyl methacrylate denture resin reinforced with glass, aramid, or nylon fibers. JProsthet Dent 2001; 86:424-7

4. Phoenix RD, Mansueto MA, Ackerman NA, Jones RE. Evaluation of mechanical and thermal properties of commonly used denture base resins. J Prosthodont 2004; 13:17-27

5. Yunus N, Rashid AA, Azmi LL, Abu-Hassan MI. Some flexural properties of a nylon denture base polymer. J Oral Rehab 2005; 32:65-71

6. Botega DM, Machado T, de Mello JA, Garcia RC, Cury AA. Polymerization time for a microwave-cured acrylic resin with multiple flasks. Braz Oral Res 2004; 18:23-8.

7. Kutsch VK, Whitehouse JW, Schermerhorn K, Bowers R. The evolution and advancement of dental thermoplastics. Dental Town 2003; 4:52-6

8. Botrtun C, Lakatos S, Sandu L, Negrutlu M, Ardelean L. Metal free removable partial dentures made of thermoplastic materials. TMJ 2006; 56:80-7.

9. Ardelean L, Bortun C, Podariu AC, Rusu LC. Some Alternatives for Classic Thermopolymerisable Acrylic Dentures.MaterialePlastice. 2012; 49:30-3

10. Hamanaka I, Takahashi Y, Shimizu H. Mechanical properties of injection-molded thermoplastic denture base resins .ActaOdontol Scand. 2011; 69:75-9.

11. Hamanaka I, Iwamoto M, Lassila L, Vallittu P, Shimizu H, Takahashi Y. Influence of water sorption on mechanical properties of injection-molded thermoplastic denture base resins. .Acta Odontol Scand. 2014; 72: 859-65.

12. Hamanaka I, Iwamoto M, Lassila LVJ, Vallittu PK, Takahashi Y. Wear resistance of injection-molded thermoplastic denture base resins. Acta BiomaterialiaOdontologicaScandinavica. 2016;2:31-7.

13. Barclay CW, Spence D, Laird WR. Intra-oral temperatures during function. J Oral Rehabil. 2005;32:886-94.

14. Ernst CP, Canbek K, euler T, Willershausen B. In vivo validation of the historical in vitro thermocycling temperature range for dental materials testing. Clin Oral Invest. 2004; 8:130-8.

15. Urban VM, Machado AL, Vergani Ce, Giampaolo eT, Pavarina AC, Almeida FG, et al. effect of water-bath post-polymerization on the mechanical properties, degree of conversion, and leaching of residual compounds of hard chairside reline resins. Dent Mater. 2009;25:662-71.

16. Durkan RK, Özdemir T, Pamir AD, Usanmaz A. Water absorption of two different denture base resins reinforced with dental ber systems. J Appl Polym Sci. 2010;117:1750-3

17. Vaidyanathan J, Vaidyanathan TK. Dynamic mechanical analysis of heat, microwave and visible light cure denture base resins. J Mater Sci Mater Med 1995;6:670-4.

18. Murata H, Taguchi N, Hamada T, Kawamu- ra M, McCabe JF. Dynamic viscoelasticity of soft liners and masticatory function. J Dent Res 2002;81:123-8.

19. Ferry JD. Viscoelastic properties of polymers. 3rd ed. New York: John Wiley \& Sons; 1980. p. 11-4.

20. Singh K, Gupta N. Injection Molding Technique for Fabrication of Flexible Prosthesis from Flexible Thermoplastic Denture Base Materials. World J Dent, 2012;3:303-7. 
21. Abuzar MA, Bellur S, Duong N, Kim BB, Lu P, Palfreyman N, et al. Evaluating surface roughness of a polyamide denture base material in comparison with poly (methyl methacrylate). J Oral Sci 2010; 52:577-81.

22. Takabayashi Y. Characteristics of denture thermoplastic resins for non-metal clasp dentures. Dent Mater J. 2010 ;29:353- 61

23. Santawisuk, W., W. Kanchanavasita, C. Sirisinha and C. Harniattisai, 2010. Dynamic viscoelastic properties of experimental silicone soft lining materials. Dental Materials Journal. 2010; 29: 454-60

24. Tolidis K, PapadogiannisD,Gerasimou P. Dynamic and static mechanical analysis of resin luting cements. J The Mech Behav Biomed Mater 2012;6:1-8.

25. Negrutiu M, Sinescu C, Romanu M, Pop D, Lakatos S. Thermoplastic resins for flexible framework removable partial dentures. Timisoara M J. 2005; 55:295-9.

26. Baeurle SA, Hotta A, Gusey AA. On the glassy state of multiphase and pure polymer materials. Polymer 2006; 47: 6243-53. 